\title{
PENDAMPINGAN PEMBELAJARAN MICROCONTROLLER BERBASIS NUVOTON DI SMKN 2 PURWOKERTO
}

\author{
LEARNING ASSISTANCE NUVOTON BASED ON \\ MICROCONTROLLER IN SMKN 2 PURWOKERTO \\ ${ }^{1)}$ Jaenal Arifin, ${ }^{2)}$ Risa Farrid C, ${ }^{3)}$ Prasetyo $\mathrm{Y}$ \\ ${ }^{1,2}$ Program Studi S1 Teknik Elektro, ${ }^{3}$ Program Studi S1 Teknik Telekomunikasi \\ Institut Teknologi Telkom Purwokerto \\ Jl. D.I Panjaitan no.128 Purwokerto \\ *Email : Jaetoga@ittelkom.ac.id
}

\begin{abstract}
ABSTRAK
Kegiatan pengabdian masyarakat ini berupa pendampingan pembelajaran bagi guru - guru SMKN 2 Purwokerto. Kegiatan pengabdian ini dilatarbelakangi karena kurangnya pengetahuan guru terkait microcontroller berbasis Nuvoton berdasarkan hasil survei yang dilakukan dengan cara wawancara. Tujuan dari kegiatan pengabdian ini adalah menambah pengetahuan terkait ilmu teknik elektro, khususnya tentang pembelajaran microcontroller. Kegiatan pengabdian masyarakat ini dilakukan selama bulan oktober tahun 2019 dengan jumlah peserta sebanyak 12 orang. Metode yang digunakan dalam pendampingan pembelajaran berbasis Nuvoton ini berupa ceramah, instalasi software pendukung, praktek langsung dan evaluasi pembelajaran. Ada 2 jenis evaluasi yang dilakukan yaitu memberikan project latihan dikelas berbasis Nuvoton dan kuesioner terkait materi yang disampaikan. Kuesioner dilaksanakan sebelum dan sesudah kegiatan pembelajaran berbasis Nuvoton. Hasil dari pendampingan pembelajaran yang telah dilakukan menunjukan bahwa adanya respon yang baik dari peserta pelatihan. Nilai evaluasi pretest sebesar 23,75\%, sedangkan nilai postest sebesar 73\%. Hal ini menunjukan bahwa ada pengaruh yang signifikan setelah dilakukan pendampingan pembelajaran berbasis Nuvoton yang telah dilakukan.
\end{abstract}

Kata kunci: Pembelajaran; Microcontroller; Nuvoton

\begin{abstract}
Learning assistance has been carried out for teachers of SMKN 2 Purwokerto as a community service activity. This activity was motivated by the lack of teacher knowledge related to Nuvoton-based microcontroller based on a survey conducted by an interview. This activity's expected goal is to increase knowledge related to electrical engineering, especially about microcontroller learning. This community service activity was carried out during October 2019 with 12 participants. The method used in this Nuvoton-based learning assistance is lecturing, installation of supporting software, direct practice, and evaluation of learning. There are two types of evaluations: providing training projects in Nuvoton-based classes and questionnaires related to the material presented. Evaluation is carried out before and after Nuvoton-based learning activities using a questionnaire. The results of the learning assistance showed a good response from the training participants. The pre test evaluation value is $23.75 \%$, while the post-test value is $73 \%$. These results shows that there is a significant effect of Nuvoton-based learning assistance.
\end{abstract}

Keywords: Learning Board; Nuvoton; Microcontroller

Submitted : 27 November 2019 Revision : 8 September 2020 Accepted : 15 September 2020 


\section{PENDAHULUAN}

Sekolah Menengah Kejuruan (SMK) merupakan salah satu bentuk satuan pendidikan formal yang menyelenggarakan pendidikan berupa kejuruan pada jenjang pendidikan menengah sebagai lanjutan dari Sekolah Menengah Pertama (SMP), Madrasah Tsanawiyah (MTs), atau bentuk lain yang sederajat atau lanjutan dari hasil belajar yang diakui sama/setara SMP/MTs. SMK sering disebut juga STM (Sekolah Teknik Menengah). SMK N 2 Purwokerto telah berdiri sejak adanya Sekolah Teknik Menegah (STM) di Purwokerto pada tahun 1958 dengan status sekolah swasta, dengan nama STM Purwokerto. Jurusan yang ada antara lain: Bangunan Gedung, Bangunan Air, Mesin, dan Listrik. Kemudian pada tahun 1968 STM Purwokerto berstatus menjadi STM Negeri dengan SK Kanda Ditjen Pendidikan Dasar Jawa Tengah Nomor: 402/XI/1968 tertanggal 26 Februari 1968, dan satu-satunya jurusan yang pertama dinegerikan adalah jurusan Bangunan.

Pada saat ini SMKN 2 Purwokerto memiliki 8 paket keahlian yaitu : Desain Permodelan dan Informasi Bangunan (DPIB), Konstruksi Gedung Sanitasi dan Perawatan (KGSP), Teknik Audio Video (TAV), Teknik Elektronika Industri (TEI), Teknik Instalasi Tenaga Listrik (TITL), Teknik Otomasi Industri (TOI), dan Teknik Pemesinan dan Multimedia. SMK N 2 Purwokerto selaku mitra pengabdian termasuk dalam mitra yang mengarah ke ekonomi produktif (Admin, no date).

Pembelajaran di SMKN 2 Purwokerto terdiri dari teori dan praktikum. Khusus pada keahlian Teknik Audio Video (TAV), Teknik Elektronika dan Industri (TEI), dan Teknik Instalasi Tenaga Listrik (TITL) mempelajari terkait bidang teknik elektro. Pembelajaran di bidang teknik elektro tentunya mengenal microcontroller atau mikropengendali. Microcontroller atau mikropengendali merupakan sistem mikroprosesor lengkap yang terkandung di dalam sebuah chip
(Id.wikipedia.org,). Chip atau ic merupakan salah satu device komponen elektronika yang dapat diprogram.

Di SMKN 2 Purwokerto, yang dipelajari adalah microcontroller jenis Alfand Vegard's Risc processor Programming (AVR). Beberapa jenis yang dipelajari seperti ATmega16, Atmega 8535, dan Atmega 128. Berikut fitur-fitur yang dimiliki microcontroller jenis AVR (Program et al., 2006; ) (Cycles) (Pardue, 2005):

a. Sistem komunikasi yang digunakan dalam meliputi RS-232, RS-485, Zigbee, dan bus komunikasi dalam industri.

b. Pulse width modulation (PWM).

c. Konversi analog ke digital (ADC) dengan bit yang dimiliki.

d. Adanya pengalamatan (addressing) dan input-output (IO)

e. Pemrograman bisa menggunakan bahasa $\mathrm{C}$.

Berikut teknologi Nuvoton yang diajarkan dalam pendampingan pembelajaran di SMKN 2 Purwokerto.

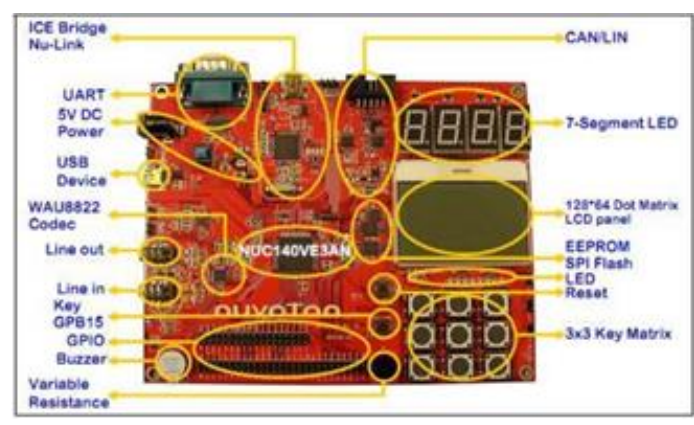

Gambar 1. Learning Board Nuvoton NUC140 (Corporation, 2012)

Dalam bidang teknik elektro banyak jenis yang bisa dipelajari. Diantaranya jenis parallax propeller, freescale, Intel 8051, ARM Processors, ATmel, Nuvoton NUC 140 LB ARM, Hitachi H8, Hitacgi $\mathrm{H}$, Hyperstone, Infineon, MIPS, NEC, NXP Semiconductors, PIC (8 bit PIC 18, 16 bit ssPIC33 atau PIC 24), Power PC 
ISE, Texas Instruments, dan Toshiba TLCS-870 (8 bit atau 16 bit).

Permasalahan pada mitra yaitu SMKN 2 Purwokerto yaitu kurangnya pembelajaran yang berbasis microcontroler. Dengan pembelajaran dalam bidang teknik elektro dan khususnya mempelajari microcontroler, pembelajaran tersebut perlu mendapat dukungan dari sisi ilmu pengetahuan, peralatan dan dukungan lainnya. Dari sisi ilmu pengetahuan teknologi yang diajarkan sebatas jenis AVR. Tidak pernah mempelajari microcontroller jenis lainnya, seperti jenis parallax propeller, freescale, Intel 8051, ARM Processors, Nuvoton NUC 140 LB ARM, Hitachi H8, Hitacgi H, Hyperstone, Infineon Microcontroller, MIPS, NEC, NXP Semiconductors, PIC (8 bit PIC 18, 16 bit ssPIC33 atau PIC 24), Power PC ISE, Texas Instruments Microcontrollers, dan Toshiba TLCS-870 (8 bit atau 16 bit).

Berdasarkan analisis situasi dan permasalahan yang diperoleh maka diperlukan pengetahuan lebih berupa kegiatan pengabdian di SMKN 2 Purwokerto dengan tema pendampingan dan pembelajaran berbasis Nuvoton. Alasan kegiatan pembelajaran ini karena di SMKN 2 Purwokerto tersebut belum pernah mengenal dan mempelajari jenis microcontroller ini.

\section{METODE}

Berikut metode pengabdian yang digunakan, terdapat 3 aktivitas yang dapat digambarkan.

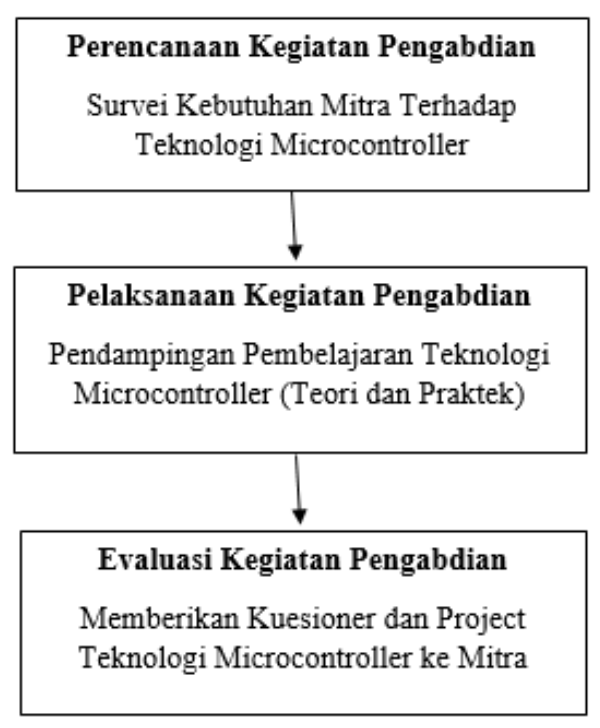

Gambar 2. Metodologi Pengabdian

Sebelum melakukan kegiatan pengabdian, langkah pertama yang harus dilakukan adalah melakukan survei terhadap kebutuhan mitra. Subjek atau mitra pengabdian pendampingan pembelajaran ini adalah SMKN 2 Purwokerto. Kebutuhan setelah melakukan survei adalah kurangnya pemahaman atau materi terkait teknologi microcontroller berbasis Nuvoton. Setelah dilaksanakan survei terhadap kebutuhan mitra, selanjutnya dilaksanakan kegiatan pengabdian masyarakat. Kegiatan ini berupa pendampingan pembelajaran teknologi berbasis Nuvoton.

Sebelum kegiatan pendampingan pembelajaran dimulai, tim pelaksana mengidentifikasi tingkat pengetahuan peserta, dengan cara memberikan pretest secara tertulis. Jumlah soal yang diujikan berjumlah 10 soal. Hasil dari pretest ditunjukkan pada tabel 1. Rerata nilai pretest adalah 1,1875. Jika dibuat dalam persentase maka hasilnya adalah $23,75 \%$. 
Tabel 1. Hasil pretest

\begin{tabular}{cc}
\hline No Soal & Nilai Kuisioner \\
\hline 1 & 1,625 \\
2 & 1,375 \\
3 & 1,000 \\
4 & 1,000 \\
5 & 1,250 \\
6 & 1,125 \\
7 & 1,125 \\
8 & 1,125 \\
9 & 1,125 \\
10 & 1,125 \\
\hline
\end{tabular}

Setelah pretest dilakukan, selanjutnya diberikan pendampingan pembelajaran terkait teknologi berbasis Nuvoton di kelas. Materi pembelajaran terdiri dari pengenalan fitur-fitur board NUC140, instralasi software pendukung, dasar input/output NUC 140, pengendalian tampilan 7 segmen, interaksi keypad dengan LCD, analog digital to converter (ADC), pulse witdh modulation (PWM), real time clock, dan aplikasi RTC. Dalam pelaksanaan kegiatan, peserta diberi project di kelas dalam aplikasi micocontroller Nuvoton. Pada sesi terakhir pembelajaran peserta diberikan post-test sebagai indikator pembelajaran yang sudah dilakukan.

\section{HASIL DAN PEMBAHASAN}

Pembelajaran bagi peserta pelatihan dalam menuntut ilmu merupakan proses mengajarkan pengetahuan dan keahlian dalam bidang tertentu serta sikap agar semakin terampil dan mampu melaksanakan tanggung jawabnya dengan baik sesuai dengan standar yang telah ada. (Mangkuprawira, 2004). Pelatihan bagi sumber daya manusia merupakan keniscayaan bagi setiap organisasi maupun lembaga, karena hampir semua orang mengakui bahwa keberhasilan suatu lembaga/organisasi sangat tergantung pada sumber daya manusia yang mengelolanya (Elfrianto, 2016).

Dalam hal ini, pelatihan merupakan bagian tak terpisahkan dari upaya untuk mengembangkan kemampuan sumber daya manusia. Melalui pelatihan yang dirancang sesuai dengan kebutuhan dan diselenggarakan dengan baik, maka peserta dapat menyerap cara-cara baru, pengetahuan baru, dan juga ketrampilan baru yang sangat bermanfaat untuk meningkatkan kualitas dan produktifitas kerjanya. Sejalan dengan perkembangan teknologi informasi yang begitu cepat, mengikuti pelatihan merupakan cara yang efektif untuk dapat mengejar ketertinggalan. Hal ini diyakini banyak kalangan dan juga menjadi cara yang lebih efisien dibandingkan dengan upaya-upaya tak terstruktur untuk belajar sendiri dari keadaan tidak mengetahui sama sekali. Dengan bekal pemahaman yang baik dari hasil pelatihan, maka peserta akan dapat mengembangkan diri dengan lebih baik dan terarah pada satu bidang tertentu yang ditekuni.

Pelatihan berbasis Nuvoton yang dikhususkan bagi guru-guru SMKN 2 Purwokerto ini dapat menambah ilmu pengetahuan dan kepercayaan diri dalam pembelajaran di kelas nantinya. Peserta berpastifipasi aktif dalam proses pembelajaran tersebut. Dengan partisipasi aktif dari peserta dalam kegiatan tersebut maka semakin bertambah pengetahuan yang didapat dan dapat menambah skill dalam bidang teknologi Nuvoton. Peningkatan pengetahuan dan keterampilan peserta pembelajaran dalam hal ini masih dalam tahapan fase koqnitif dan fase asosiatif. Dalam proses pembelajaran menuntut ilmu pengetahuan dan menambah keterampilan sebaiknya harus melewati fase koqnitif, fase asosiatif, dan fase autonomi (Randal, \& Arnold, 2010).

Fase kognitif merupakan fase dimana peserta dapat memperoleh ilmu pengetahuan dan ketrampilan tertentu dari skill yang ingin dikuasai. Fase asosiatif 
merupakan fase dimana peserta melakukan aktivitas kembali dengan mempraktekkan ilmu yang sebelumnya diperoleh. Di fase ini, peserta melakukan aktivitas pemrograman pada microcontroller berbasis Nuvoton dengan bahasa $\mathrm{C}$ dan melakukan croscheck kembali jalur input dan output dari learning board Nuvoton.

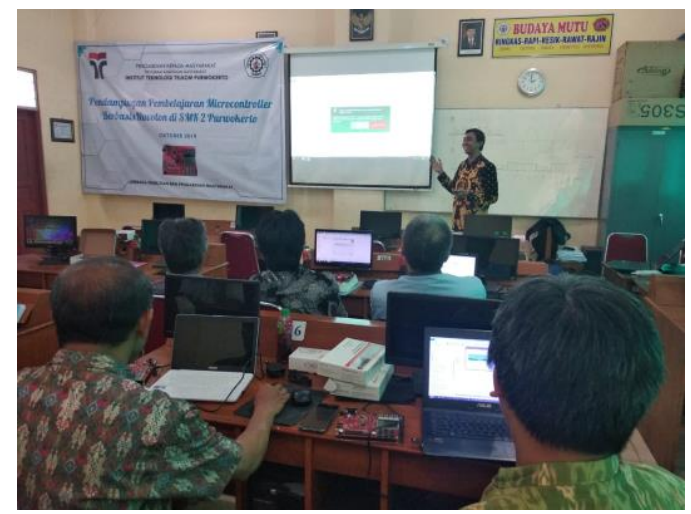

Gambar 3. Kegiatan Pendampingan Pembelajaran Microcontroller

Pendampingan pembelajaran yang telah dilaksanakan menggunakan metode experiential learning. Gambr 3 merupakan salah satu foto kegiatan yang dilaksanakan di kelas dengan metode expreriential learning.

Metode ini melibatkan peserta untuk aktif di kelas. Peserta melakukan komunikasi berupa diskusi dengan pemateri. Pembelajaran dilakukan dengan cara menerangkan teori teknologi Nuvoton dan praktek langsung di kelas dengan cara membuat program yang telah dijelaskan sebelumnya. Pendampingan pembelajaran ini berjalan sukses dan lancar. Suksesnya pembelajaran ini berkat sarana dan prasarana yang memadai di lingkungan SMKN 2 Purwokerto. Adapun sarana tersebut misalnya 1 (satu) trainer Nuvoton dipegang 1 peserta/orang dan didampingi 1 (satu) asisten dalam membuat program. Adanya infokus di ruang kelas, pemateri menerangkan secara step by step dan terstruktur. Hal ini memudahkan peserta dalam menerima materi yang diajarkan di kelas selama proses pendampingan pembelajaran.

Peserta pembelajaran teknologi berbasis Nuvoton sangat aktif dalam mengikuti kegiatan pelatihan. Dari awal materi berupa pengenalan fitur-fitur borad NUC140, Instalasi software board NUC140, dasar input/output NUC 140, Pengendalian tampilan 7 segment, Interaksi keypad dengan LCD, Analog to Digital Converter (ADC), Pulse width modulation (pwm), Real time clock ( $\mathrm{rtc}$ ), dan terakhir materi berupa aplikasi rtc. Dalam pembelajaran di kelas, peserta aktif bertanya dan diskusi dengan pemateri. Sebagai tambahan pemrograman peserta pelatihan diberikan project sederhana terkait program berbasis Nuvoton. Project sederhana yang diberikan pada saat pendampingan pembelajaran berupa membuat program led berkedip, led berjalan kiri-kanan, dan menampilkan detik jam dengan memanfaatkan seven segment yang tersedia pada trainer Nuvoton. Hasil yang diperoleh adalah peserta mampu membuat program tersebut dengan baik, namun ada beberapa peserta yang tetap dipandu dalam mengerjakan program tersebut.

Peserta pembelajaran memberikan penilaian terhadap proses pembelajaran teknologi berbasis Nuvoton. Penilaian pembelajaran berupa memberikan masukan yang ada dikuisioner. Tabel 2 menunjukkan hasil dari kuisioner setelah pembelajaran dilaksanakan. Hasil dari kuisioner tersebut sebesar 3,65. Jika diubah menjadi persentase, maka hasilnya adalah 73\%. Penilaian tersebut merupakan salah satu bahan evaluasi untuk bagi pemateri supaya memberikan layanan pembelajaran yang lebih baik lagi. 
Jaenal Arifin, Risa Farrid C, Prasetyo Y

Pendampingan Pembelajaran Microcontroller Berbasis Nuvoton di SMKN 2 Purwokerto

Tabel 2. Hasil post test

\begin{tabular}{cc}
\hline No Soal & Nilai Kuisioner \\
\hline 1 & 3,250 \\
2 & 2,875 \\
3 & 3,250 \\
4 & 4,000 \\
5 & 3,875 \\
6 & 4,125 \\
7 & 4,250 \\
8 & 4,125 \\
9 & 3,500 \\
10 & 3,250 \\
\hline
\end{tabular}

Tabel 2 dapat dijadikan acuan dalam menunjukkan nilai kepuasan peserta pembelajaran. Nilai persentase kepuasan peserta pembelajaran sebesar $73 \%$. Hasil penilaian terhadap pemateri pembelajaran merasa terbantu dalam mendapatkan ilmu baru tentang teknologi microcontroller berbasis Nuvoton. Peserta merasa puas dan senang dengan cara yang digunakan pemateri dalam menyampaikan ilmunya. Penyampaian materi dengan cara memberikan materi teori dan praktek langsung di kelas.

\section{SIMPULAN}

Pembelajaran microcontroller berbasis Nuvoton yang dilaksankan di SMKN 2 Purwokerto mampu meningkatkan pengetahuan dalam bidang elektronika dan pemograman. Ilmu pengetahuan yang didapatkan peserta diharapkan mampu dimanfaatkan dalam pembelajaran siswa didiknya. Dengan melihat kondisi yang ada di SMKN 2 Purwokerto, rencana ke depan melakukan pendalaman materi terkait teknologi berbasis Nuvoton. Pendalaman materi diperlukan supaya materi yang diberikan terus berkelanjutan. Rencana tindak lanjut lain adalah melakukan pendampingan pembuatan proposal untuk mendapatkan hibah teknologi berbasis Nuvoton dari Academic Program from Taiwan.
Mengingat di SMKN 2 Purwokerto belum memiliki trainer microcontroller berbasis Nuvoton, maka tujuan dari pembuatan dan mendapatkan hibah teknologi berbasis Nuvoton adalah untuk mendapatkan trainer microcontroller Nuvoton.

\section{DAFTAR PUSTAKA}

Admin, S. N. 2 P. (n.d.). Profile SMKN 2 Purwokerto. Retrieved from https://smkn2purwokerto.sch.id/

Corporation, N. T. (2012). NuMicro TM NUC140 Data Sheet ARM Cortex TM -M0 NuMicro TM Family NUC140 Data Sheet, 1-77.

Cycles, W. E. (n.d.). Datasheet ATmega16. In Configurations (pp. 1-26). Atmel. Retrieved from www.atmel.com

Id.wikipedia.org. (n.d.). Pengendali_mikro. Retrieved from https://id.wikipedia.org/wiki/Pengen dali_mikro

Elfrianto. (2016). Manajemen Pelatihan Sumber Daya Manusia Dalam Meningkatkan Mutu Lulusan. EduTech: Jurnal Ilmu Pendidikan Dan Ilmu Sosial, 2(2), 46-58. https://doi.org/10.30596/edutech.v2i $\underline{2.596}$

Mangkuprawira, S. (2004). Manajemen Sumber Daya Manusia Strategik. Jakarta: Ghalia Indonesia.

Pardue, J. (2005). C Programming for Microcontrollers. Smiley micros. Smiley Micros. https://doi.org/0976682206

Program, N., Memories, D., Operation, T. R., Features, P., Modes, C., Mode, C., ... Grades, S. (2006). Datasheet ATmega8535 (pp. 1-22). Retrieved from www.atmel.com

Randal, R. \& Arnold, J. (2010). Understanding Human Behaviour in 
the Workplace. London: Pearson

Education Limited. 